\title{
BUEN VIVIR - SUAS ORIGENS E CONSOLIDAÇÃO NA AMÉRICA DO SUL
}

\section{BUEN VIVIR - ORIGINS AND CONSOLIDATION IN SOUTH AMERICA}

\author{
Helio Augusto Teixeira Silva ${ }^{1}$ \\ Kerley dos Santos Alves ${ }^{2}$
}

\begin{abstract}
Resumo
O presente artigo trata do conceito de Buen Vivir que pode ser entendido como filosofia fluida de vida originada nos povos Andinos que consagrou a natureza como sujeita de direitos na Constituição do Equador em 2008. A abordagem dessa temática buscou verificar suas nuances e expansão junto às nações na América do Sul e ainda suas críticas em relação ao progresso tecnológico da humanidade em detrimento da natureza. Por meio de uma pesquisa bibliográfica e documental com análise de artigos científicos e livros e o estudo de autores como Alberto Acosta, Ferdinand Lassalle, Ronald Dworkin, Romeu Thomé, entre outros, foi avaliado o equilíbrio entre o progresso da humanidade e a preservação da natureza, de modo a compreender como o Buen Vivir tem sido incorporado na legislação brasileira. Foram analisados alguns princípios constitucionais e ambientais que se aplicam à matéria da proteção ambiental, que foram desenvolvidos e aperfeiçoados após as conferencias mundiais que trataram do meio ambiente. Ao final verificou-se que a Filosofia do Buen Vivir, também foi incorporada na Constituição brasileira e nas normas infraconstitucionais, com a criação de institutos que protegem a utilização indiscriminada dos recursos naturais, fazendo da natureza e do meio ambiente equivalentes na condição de sujeitos de direito no ordenamento jurídico brasileiro.
\end{abstract}

Palavra-chave: Natureza; Legislação brasileira; Princípios constitucionais; desenvolvimento.

\begin{abstract}
This article deals with the concept of Buen Vivir, which can be understood as a fluid philosophy of life originated in the Andean peoples who consecrated nature as obtaining rights in the Constitution of Ecuador in 2008. The approach to this theme sought to verify its nuances and expansion among nations in South America and even its criticisms in relation to the technological progress of humanity at the expense of nature. Through a bibliographical and documentary research with analysis of scientific articles and books and the study of authors such as Alberto Acosta, Ferdinand Lassalle, Ronald Dworkin, Romeu Thomé, among others, the balance between the progress of humanity and the preservation of nature was evaluated, in order to understand how Buen Vivir has been incorporated into Brazilian
\end{abstract}

\footnotetext{
*Artigo Original: Recebido em 17/10/2021 - Aprovado em 07/11/2021.

${ }^{1}$ Graduado em Direito, Pós-graduado em Gestão Pública e Controle com foco em Resultados, Mestrando em Sustentabilidade Sócio Econômica e Ambiental, Universidade Federal de Outo Preto (UFP), Procurador do Município de Ouro Preto, Ouro Preto/MG, Brasil.e-mail: helio-direito@hotmail.com ORCID: https://orcid.org/my-orcid?orcid=0000-0003-4683-3254

2 Pós-Doutora em Democracia, Cidadania e Direito, Doutora em Psicologia, Professora da UFOP, Ouro Preto/MG, Brasil. e-mail: kerleysantos@yahoo.com.br ORCID: https://orcid.org/0000-0001-6215-3457
} 
legislation. Some constitutional and environmental principles that apply to the matter of environmental protection were eliminated, which were developed and improved after the world conferences that dealt with the environment. In the end, it was found that the Buen Vivir Philosophy was also incorporated in the Brazilian Constitution and in the infra-constitutional norms, with the creation of institutes that protect the indiscriminate use of natural resources, making nature and the environment equivalent in the condition of subject of law in the Brazilian legal system.

Keywords: Nature; Brazilian legislation; Constitutional principles; Development.

\section{Introdução}

A Constituição do Equador, promulgada em 2008, chamou atenção das demais nações ao consagrar a Natureza como sujeita de Direitos individuais. Segundo Souza (2014), a constituição foi aprovada pela população Equatoriana por referendo, com massiva participação indígena, no dia 28 de setembro de 2008 , recebendo mais de $64 \%$ dos votos.

Neste contexto introduziu-se o conceito de direitos da natureza, de modo que a "Mãe Terra" passou a ser tratada como um organismo vivo, apto a receber a tutela constitucional. Tal previsão veio expressa no capítulo sétimo da referida Constituição que, em seu artigo 71 determina:

Art. 71. La naturaleza o Pacha Mama, donde se reproduce y realiza la vida, tiene derecho a que se respete integralmente su existencia y el mantenimiento y regeneración de sus ciclos vitales, estructura, funciones y procesos evolutivos.

Toda persona, comunidad, pueblo o nacionalidad podrá exigir a la autoridad pública el cumplimiento de los derechos de la naturaleza. Para aplicar e interpretar estos derechos se observarán los principios establecidos en la Constitución, en lo que proceda.

El Estado incentivará a las personas naturales y jurídicas, y a los colectivos, para que protejan la naturaleza, y promoverá el respeto a todos los elementos que forman un ecosistema. (ECUADOR, 2008)
Verificando o conteúdo do texto, passou-se a buscar a origem filosófica da consagração desse Direito Constitucional, e o conteúdo existente na expressão Pacha mama, encontrando na filosofia do Buen Vivir o seu embrião.

Célio Turino (2020) ensina que o Buen Vivir é uma filosofia de vida universal e em construção, originada nos povos Andinos que parte da cosmologia e do modo de vida ameríndio, mas que está presente nas mais diversas culturas.

Ainda segundo Turino (2020), o Buen Vivir busca a mais intensa interação possível entre o homem e a natureza, sendo esta a Pacha mama. Dessa forma, Buen Vivir significa viver em aprendizado e convivência com a natureza, fazendo-nos reconhecer que somos parte dela e não podemos continuar a viver à parte dela.

Para este modo de vida, o progresso e o desenvolvimento são incompatíveis com a preservação da natureza e seus valores, razão pela qual a ruptura com o atual modelo desenvolvimentista e tecnológico é o início de sua ascensão.

Assim, este modo de vida se consagrou na Constituição equatoriana em 2008, ao incluir a natureza, como sujeita de direitos sendo, portanto, conforme Turino (2020), parte da certidão de nascimento da nação do Equador a partir deste momento.

No entanto, sua inclusão como direito constitucional impõe uma análise quanto à sua categoria jurídica e suas implicações nas legislações infraconstitucionais. Ademais disto, mister analisar seus impactos concernentes à mudança da forma de vida e resposta social ante aos seus anseios desenvolvimentistas.

A compatibilização dessas duas visões de mundo será o mote deste artigo, verificando como a legislação 
brasileira tem se comportado, em paralelo ao Buen Vivir e sua expansão, notadamente no Equador. Neste ponto haverá uma análise da legislação brasileira em matéria ambiental, demonstrando como o nosso ordenamento jurídico trata a filosofia do Buen Vivir em consonância com o desenvolvimento e progresso social.

\section{O Buen Vivir - significado e suas origens}

Como dito, Buen Vivir é um conceito fluido de um modo de vida que se origina nos povos andinos notadamente entre os indígenas da Bolívia e do Equador. Como filosofia de vida, é universal e está em construção, tendo nascido nos povos Andinos partindo da cosmologia e do modo de vida ameríndio, mas que está presente nas mais diversas culturas. (TURINO, 2013).

Segundo Tadeu Breda, jornalista responsável pela tradução do livro Buen Vivir de Alberto Acosta Espinosa (ACOSTA, 2016) 'Buen Vivir' ou 'Vivir bien' são traduções mais fiéis à exegese das expressões utilizadas pelos povos indígenas da América Latina (p.ex. 'sumak kawsay' em quechua ou 'suma qamaña' em aymara).

O livro Buen Vivir foi escrito por Alberto Acosta Espinosa que, segundo Turino (2020), é um dos principais ideólogos do início da Revolução Cidadã do Equador, sendo responsável pelo plano de governo da Alianza País, partido encabeçado por Rafael Correa que ascendeu à presidência do Equador em 2007.

Alberto Acosta Espinosa também foi Ministro de Energia e Minas no Equador, além de ter dirigido os trabalhos da primeira Assembleia Constituinte do planeta a reconhecer os direitos à Natureza, entendida por ele como nossa Pacha Mama, a Mãe Terra.

É nesse contexto, portanto que se disseminou o conceito do Buen Vivir, como uma forma de vida em que a natureza deve ser protagonista e sujeita de direitos, não sendo um conceito estático, mas em construção, apto a receber influências que podem alterar a visão de mundo,

Vale destaque ainda nos dizeres de Dilger (2017) “o Buen Vivir é um conceito aberto, de origem latinoamericana, que está constituindo em um aporte genuíno ao debate da esquerda mundial do século 21 ”.
Trata-se, portanto de um conceito que se engaja filosófica e politicamente aos movimentos progressistas que, conforme Dilger (2017), participaram ativamente da gestão dos países latinoamericanos ao longo dos últimos (quinze) anos.

Ao alçar a Natureza como sujeita de direitos na Constituição do Equador, a filosofia do Buen Vivir ganhou um caráter institucionalizado e mantém seu objetivo, qual seja de que esta institucionalização constitucional seja propagada em mais países e continentes.

Segundo Acosta (2016),

Desde meados do século XX, um
fantasma percorre o mundo. Este
fantasma é o desenvolvimento.
E embora a maioria das pessoas,
certamente, não acredite em
fantasmas, pelo menos em
algum momento acreditou no
"desenvolvimento", se deixou
influenciar pelo "desenvolvimento",
perseguiu o "desenvolvimento",
trabalhou pelo "desenvolvimento",
viveu do "desenvolvimento" É muito
provável que siga fazendo isso ainda
hoje. (ACOSTA, 2016, p. 43).

Verifica-se a ideia de que a busca do ser humano pelo desenvolvimento é a raiz de toda a degradação pela qual passa o meio ambiente, pelo que, este deve ser defendido. Segundo Shiraishi Neto e Araújo (2015, p. 385) outra explicação para o surgimento da necessidade de constitucionalização do Buen Vivir ressai do quadro identificado até a instalação da assembleia constituinte: o de que estamos a viver em uma sociedade de risco.

Ainda conforme Shiraishi Neto e Araújo (2015, p. 386), essa sociedade de risco exigia uma proposta em que se pudesse questionar o modelo de desenvolvimento em si, demonstrando que os riscos causados por esse modelo têm o condão de comprometer a sobrevivência da vida humana e não humana, especialmente o sistema de interação entres os diferentes seres, com especial destaque para Pacha mama.

Concluem que seria, assim, necessário demolir as estruturas do constitucionalismo eurocêntrico 
que não reconheceria a alteridade como princípio fundante de uma ordem política em que todos efetivamente tivessem voz e pudessem influir decisivamente nos destinos do país. Isso resta bem claro da leitura do preâmbulo da Constituição do Equador:

Reconociendo nuestras raíces milenarias, forjadas por mujeres y hombres de distintos pueblos; Celebrando a la naturaleza, la Pacha Mama, de la que somos parte y que es vital para nuestra existencia; Invocando el nombre de Dios y reconociendo nuestras diversas formas de religiosidad y espiritualidad; Apelando a la sabiduría de todas las culturas que nos enriquecen como sociedad; Como herederos de las luchas sociales de liberación frente a todas las formas de dominación y colonialismo; Y con un profundo compromiso con el presente y el futuro, Decidimos construir una nueva forma de convivencia ciudadana, en diversidad y armonía con la naturaleza, para alcanzar el Buen Vivir, el sumak kawsay; Una sociedad que respeta, en todas sus dimensiones, la dignidad de las personas y las colectividades; Un país democrático, comprometido con la integración latinoamericana - sueño de Bolívar y Alfaro-, la paz y la solidaridad con todos los pueblos de la tierra; y; En ejercicio de nuestra soberanía, en Ciudad Alfaro, Montecristi, provincia de Manabí, nos damos la presente: Constitución De La Republica Del Ecuador. (ECUADOR, 2008).

Assim o Buen Vivir é tratado de maneira diferente na nova Constituição equatoriana. É apresentado como "direitos do Bem-Viver", que incluem alimentação, ambiente sadio, água, comunicação, educação, moradia, saúde, entre outros. Nesta perspectiva, expressa um conjunto de direitos que, por sua vez, estão no mesmo plano hierárquico dos demais direitos reconhecidos pela Constituição.
Em paralelo à constituição brasileira, o Buen-vivir recebeu a mesma ênfase dos direitos e garantias fundamentais que se referem às pessoas e grupos de atendimento prioritário, comunidades, povos e nacionalidades, participação, liberdade incluindose a Natureza em invocação à sabedoria dos povos antigos.

Conforme explicitado acima, o Buen Vivir já aparece no preâmbulo da Constituição Equatoriana, como meta a ser alcançada. De acordo com Miranda (1977), o preâmbulo de uma Constituição se consubstancia como uma

proclamação mais ou menos solene, mais ou menos significante, anteposta ao articulado constitucional não é componente necessário de qualquer Constituição, mas tão somente um elemento natural de Constituições feitas em momentos de ruptura histórica ou de grande transformação político-social. (MIRANDA, 1977).

Mesmo não possuindo força normativa, o preâmbulo, por não significar uma norma constitucional propriamente dita, não poderá prevalecer contra o texto expresso da Constituição Federal, mas pode ser usado, todavia, como linha interpretativa do texto constitucional, por traçar diretrizes políticas, filosóficas e ideológicas.

Nesse contexto, destaca-se o fato de que a Constituição Equatoriana apresenta uma seção dedicada ao "regime do Buen Vivir" em que se indicam dois componentes principais: os referidos à inclusão e à equidade (tais como educação, saúde, segurança social, moradia, comunicação social, transporte, ciência, entre outras); e os focados na conservação da biodiversidade e manejo dos recursos naturais (por exemplo, proteção da biodiversidade, solos e águas, energias alternativas, ambiente urbano, entre outros.

Segundo Novelino (2009) os direitos fundamentais não surgiram simultaneamente, mas em períodos distintos conforme a demanda de cada época, tendo esta consagração progressiva e sequencial nos textos constitucionais dado origem à classificação em gerações. É, portanto, com esse arcabouço jurídico, filosófico e ideológico que se passa a analisar o 
enquadramento dos direitos da natureza no âmbito do estudo das normas constitucionais.

\section{Gerações de direitos constitucionais}

Ao incluir a natureza como sujeita de Direitos em âmbito constitucional, o Buen Vivir concretiza-se como uma ideia que busca ser institucionalizada, rompendo as fronteiras dos povos andinos colocandose como um Instituto de Direito Constitucional.

Neste ponto mister entender sua dimensão e importância no contexto atual e em regimes democráticos. Para Ferdinand Lassalle (2000):

Constituição é um pacto juramentado entre o rei e o povo, estabelecendo os princípios alicerçais da legislação e do governo dentro de um país". Ou generalizando, pois existe também a Constituição nos países de governo republicano: "A Constituição é a lei fundamental proclamada pelo país, na qual baseia-se a organização do Direito público dessa nação. (LASSALLE, 2000, p. 6).

Neste paradigma, tem-se que o Buen Vivir passa a fazer parte do DNA de uma nação, cuja certidão de nascimento é sua Constituição. Uma nova Constituição inaugura uma ordem Constitucional em que os demais ramos do Direito ficam, a ela sujeitos, tendo-se em conta a supremacia constitucional em relação às demais leis infraconstitucionais.

Ainda segundo Lassalle (2000) uma Constituição, para reger uma nação, necessita a aprovação legislativa, isto é, tem que ser também lei. Todavia, não é uma lei como as outras, uma simples lei: é mais do que isso. Entre os dois conceitos não existe somente afinidade; há também diferenças. Esta, que faz que a Constituição seja mais do que simples lei, poderia demonstrá-lo com centenas de exemplos.

Em um país, por exemplo, não se vê protestos em razão de constantemente serem aprovadas novas leis; pelo contrário, é sabido que se torna necessário sempre a criação de leis. Lassalle (2000) ainda ensina que, não se pode decretar-se uma única lei que seja, nova, sem alterar a situação legislativa vigente no momento da sua aprovação, pois se a nova lei não motivasse modificações no aparelhamento legal vigente, seria absolutamente supérflua e não teria motivos para ser a mesma aprovada.

Assim, Lassalle (2000) relembra que não há protestos quando as leis são modificadas, pois notamos, e estamos cientes disso, que é esta a missão normal e natural dos governos. Porém as alterações na Constituição, geram protestos, os quais são, por vezes, ruidosos. Assim, questiona-se: Qual é a origem dessa diferença?

Trata-se de uma diferença tão latente, que segundo Lassalle (2000) existem Constituições que dispõem taxativamente de mecanismos que proíbem sua alteração; noutras, consta que para reformá-la não é o bastante que uma simples maioria assim o deseje, mas que será necessário obter dois terços dos votos do Parlamento.

Noutro giro, existem ainda algumas onde se declara que não é da competência dos Corpos Legislativos sua modificação, nem mesmo unidos ao Poder Executivo, senão que para reformá-la deverá ser nomeada uma nova Assembleia Legislativa, ad hoc criada expressa e exclusivamente para esse fim para que a mesma se manifeste acerca da oportunidade ou conveniência de ser a Constituição modificada.

Todos esses fatos demonstram que, no espírito unânime dos povos, uma Constituição deve ser qualquer coisa de mais sagrado, de mais firme e de mais imóvel que uma lei comum. Daí vislumbrase a importância jurídica da inclusão do Buen Vivir na constituição equatoriana e, por consequência, da Natureza como sujeita de direitos em seu ordenamento jurídico.

Entendida a importância da inclusão do Buen vivir na Constituição do Equador, mister que haja compreensão quanto à sua natureza jurídica. Isso se deve ao fato de que uma constituição é formada, ao longo de seu texto, por princípios e regras, as quais são alvo de diversas classificações, entre as quais, algumas passa-se a expor.

\section{Princípios jurídicos, regras e suas diferenças}

O fato da Natureza ser alçada à categoria de sujeita de Direitos, faz conferir relevo à sua existência e, noutro giro, imputa responsabilidades ao homem quando da sua interação com ela. Ocorre, todavia, 
que sua inclusão como sujeita de Direitos ainda não significa que esta faz jus à Direitos absolutos ou soberanos, mas sim que há mais um instituto ou princípio jurídico que deverá ser compatibilizado com os demais coexistentes.

Conforme ensinam Manuel Atienza e Juan Ruiz Manero (2017), um dos temas mais discutidos na teoria do Direito das duas últimas décadas é, sem dúvida nenhuma, o dos princípios. "O debate-como todo o mundo sabe -se inicia com um trabalho de Dworkin de 1967 (Dworkin, 1978), ainda que os "princípios jurídicos" (ou os "princípios gerais do Direito") sejam velhos conhecidos (mesmo que talvez não mais que conhecidos) dos juristas".

Ainda segundo Atienza e Manero (2017), o Código Civil austríaco de 1811 já continha previsão sobre os princípios gerais do Direito, e continuaram mantendo essas previsões desde então. Igualmente há muitos outros textos legislativos como o Código Civil italiano de 1865 , o espanhol de 1889 e o art. 38 do Estatuto do Tribunal Internacional de Justiça de Haya. Igualmente nos trabalhos de dogmática jurídica e nas decisões jurisprudenciais, a referência aos princípios é, pode-se dizer, um lugar comum; e a reflexão sobre os mesmos não esteve também ausente da teoria ou Filosofia do Direito anterior a Dworkin.

No entender de Cachichi (2009), há algum consenso de que a elaboração teórica de Ronald Dworkin (1978) foi a primeira que frisou com mais nítidos contornos essa distinção entre princípios e regras.

Este fez, opondo-se ao positivismo jurídico, especialmente da versão do jurista Herbert Hart (2002). Consignou textualmente Dworkin: "Quero lançar um ataque geral contra o positivismo e usarei a versão de H. L. A. Hart como alvo, quando um alvo específico se fizer necessário" (HART, 2002, p. 35).

Por sua vez, "Alexy, partindo das considerações de Dworkin (2002 apud ÁVILA, 2007, p. 37), precisou ainda mais o conceito de princípios", assertiva esta que Sobrevilla (1996, p. 97) confirmou: Robert Alexy propôs de início um modelo jurídico de regras e princípios em seu artigo 'Zum Begriff des Rechtsprinczips', no qual comentava e criticava a distinção entre regras e princípios de Ronald Dworkin e, por sua vez, tomava-a como ponto de partida para sua própria teoria. Assim, desenvolveu o modelo jurídico de regras e princípios em seu livro
Theorie der Grundrechte, que foi seu trabalho de habilitação.

Neste trabalho, Alexy (1988) realizou uma diferenciação entre princípios e regras, classificandoas como sendo espécies do gênero norma. Cachichi (2009) relata, citando Alexy que regras são normas com a mesma estrutura deôntica que devem ser cumpridas. Princípios, por sua vez, são normas a serem cumpridas na maior medida possível dentro de possibilidades jurídicas e reais existentes (ALEXY, 1988 p. 90).

O mesmo Alexy (1988), noutra obra, expõe com cirúrgica precisão:

Há, portanto distintos graus de cumprimento. Se se exige a maior medida possível de cumprimento em relação com as possibilidades jurídicas e fáticas, se trata de um princípio. Se tão somente se exige uma determinada medida de cumprimento, se trata de uma regra. (ALEXY, 1988, p. 144).

Tal diferenciação importa na medida em que, ao incluir a Natureza como sujeita de Direitos em âmbito constitucional, gera a necessidade de mensuração quanto ao efetivo grau de coercitividade que será imposto à sociedade, a fim de dar cabo ao seu cumprimento.

Isto, pois é o cerne da diferença, a qual, como se vê, denuncia a importância do enquadramento da Natureza como sujeita de Direitos em razão das corriqueiras contradições entre normas como fator de delimitação entre suas espécies.

Ainda conforme Alexy (1988) "a diferença entre regras e princípios mostra-se com maior clareza nos casos de colisões entre princípios e de conflitos entre regras". Pode-se dizer, pois, que a colisão de princípios e o conflito de regras são instrumentos dos quais pode o intérprete lançar mão ao fazer a distinção entre princípios e regras.

Em se tratando de Direitos consagrados na Constituição, especialmente dos direitos sociais, é relevante lembrar que estes, estão consagrados na Constituição em normas jurídicas de ambas as espécies, isto é, como regras e como princípios. 
Ambos dizem aquilo que deve ser, sendo os princípios mais abstratos e aplicados a um número indeterminado de situações e as regras são proposições normativas aplicáveis sob a forma de tudo ou nada. No caso da regra, o dever é o de adoção da conduta nela descrita.

Quanto ao princípio, o dever é o de promover uma finalidade. Na maioria das vezes, os princípios justificam as regras. Assim, em uma hipotética situação em que o Direito à vida colidir com o Direito à Natureza, ponderar-se-á ambos, como em uma balança, concluindo no caso concreto, qual prevalecerá.

É nesse contexto que, segundo Souza (2014), não parece nítida a diferença entre a Constituição equatoriana e a brasileira, a qual também possui dispositivos relativos ao direito ambiental, tendo reservado um capítulo inteiro para a disciplina do meio ambiente. Na Constituição brasileira, o sujeito do direito são as pessoas, a quem se garante o direito a um meio ambiente ecologicamente equilibrado, sendo a natureza vista como um bem coletivo.

Souza (2014) ainda ensina que para o melhor entendimento do texto constitucional equatoriano, é preciso destacar que o Equador se define como um Estado Plurinacional, ou seja, um país onde se prega a tolerância da diversidade, composto por povos e etnias distintos, todos compartilhando a visão de que a Mãe Terra deve ser considerada muito mais como "alguém" do que como "algo", o que, por via de consequência, a torna um sujeito passível de direitos.

A constituição equatoriana, portanto, estabeleceu o Buen vivir e, portanto, a Natureza como regra constitucional e, na busca do equilíbrio entre a natureza e as necessidades dos seres humanos, a Constituição do Equador superou a tradicional previsão constitucional do direito a um ambiente saudável, presente na maioria dos textos constitucionais latino-americanos, e inclusive no texto constitucional brasileiro.

Ainda conforme lição de Souza (2014), isso quer dizer que o direito a um meio ambiente saudável diz respeito à proteção dos direitos humanos, sendo, inclusive, o art. 225 da Constituição Brasileira considerado como direito fundamental. No entanto, tais direitos não significam direitos da natureza.

Assim, o constituinte equatoriano entendeu que não seria possível assegurar o direito a um meio ambiente saudável sem respeitar os direitos da natureza, e por tal motivo, elevou a Pacha Mama a titular de direitos, indicando a necessidade de se estabelecer um vínculo honesto entre direitos humanos e direitos da natureza.

Ressalte-se que o reconhecimento da natureza como titular de direitos não permite a conclusão de que a mesma goza de qualquer prevalência ou superação em relação aos direitos humanos. Com esses fundamentos estabelecidos, sendo a natureza "algo" ou "alguém" que surge a ideia de consolidação do meio ambiente como um direito humano não mais suscetível a retrocessos. Da mesma forma, as tecnologias e o desenvolvimento da ciência e da humanidade, tampouco retrocederão, o que se consubstancia pela ideia do Efeito Cliquet, que será a seguir abordado.

\section{Efeito cliquet}

Alberto Acosta (2016) tece críticas ao modelo desenvolvimentista empregado pela humanidade, com a disseminação de tecnologias e capital. Esse desenvolvimento impõe à humanidade conquistas que não retrocederão.

É neste ponto que se consagra a aplicação do Princípio da Proibição de Retrocesso, ou efeito cliquet. O termo Efeito Cliquet é de origem francesa e a palavra "cliquet" se traduz, literalmente, por catraca, e, segundo Albanesi (2008), a expressão "cliquet" é utilizada pelos alpinistas e define um movimento que só permite o ao mesmo subir, não lhe sendo possível retroceder, em seu percurso.

São pinos de sustentação colocados sempre acima do alpinista e que só permitem movimentos de subida. Por isso, usar a expressão Efeito Cliquet ou Efeito Catraca para traduzir a proibição ou vedação do retrocesso de direitos fundamentais, os quais não deveriam retroceder em hipótese alguma.

Entende-se como Direitos fundamentais, na lição de Fachini (2019) os direitos fundamentais são direitos protetivos, que garantem o mínimo necessário para que um indivíduo exista de forma digna dentro de uma sociedade administrada pelo Poder Estatal.

Os direitos fundamentais são baseados no princípio da dignidade da pessoa humana e, portanto, não podem ser extintos ou mitigados. Daí emana a ideia de vedação ao retrocesso em matéria de direitos 
fundamentais, aplicando-se à previsão constitucional equatoriana da proteção aos Direitos da Natureza e ao artigo 225 da Constituição brasileira, o qual confere a proteção ao Meio Ambiente.

Segundo Canotilho (2002, p. 336) este princípio recebe também várias outras denominações: vedação de retrocesso social, princípio do não retrocesso social, princípio do não retorno da concretização, proibição da contrarrevolução social ou da evolução reacionária, ratchet effect (no inglês), entre outras.

Aplicado aos Direitos sociais em diversos países, o Efeito Cliquet pode ter sua ótica amplificada para o desenvolvimento atingido pela sociedade pósmoderna, tão criticado por Alberto Acosta (2016).

Essa necessária introdução serve para demonstrar que a humanidade não retrocederá em suas conquistas. Desta forma, a aplicação da filosofia do Buen Vivir deve buscar sua harmonização ao desenvolvimento já existente, não para demover a humanidade de suas vitórias, mas para enxertar a natureza como mais uma conquista a ser alcançada.

\section{0 efeito cliquet em matéria ambiental}

O efeito cliquet também é aplicado em matéria ambiental, pois o direito ao meio ambiente ecologicamente equilibrado possui status de direito fundamental e, as garantias de proteção ambiental já conquistadas, não podem retroagir. É inadmissível o recuo da salvaguarda ambiental para níveis de proteção inferiores aos já consagrados, a não ser que as circunstâncias de fato sejam significativamente alteradas.

Esse princípio da Proibição ao retrocesso tem por escopo obstar medidas legislativas e executivas que implementem uma desproteção relação ao direito ambiental. Não se pode, por exemplo, revogar uma lei que proteja o meio ambiente sem, no mínimo, substituí-la por outra que ofereça garantias com eficácia, no mínimo, similar. Os poderes públicos devem atuar sempre no sentido de avançar progressivamente na proteção dos recursos naturais.

Nos dizeres de Garcia e Thomé (2015) o Superior Tribunal de Justiça -STJ, entende que "essa argumentação busca estabelecer um piso mínimo de proteção ambiental, para além do qual devem rumar as futuras medidas normativas de tutela, impondo limites a impulsos revisionistas da legislação".
7 A proteção ao meio ambiente na legislação do Brasil

Há tempos no Brasil, o ordenamento jurídico tem adotado medidas para garantir a proteção ao meio ambiente. Essas baseiam-se em princípios estruturantes das ciências jurídicas e norteiam a edição de normas em matéria ambiental.

$\mathrm{Na}$ lição de Campos (2018) princípios são os mandamentos básicos e fundamentais nos quais se alicerça uma ciência. São as diretrizes que orientam uma ciência e dão subsídios à aplicação das suas normas.

Os princípios do Direito Ambiental, no ordenamento jurídico brasileiro, estão voltados para a finalidade básica de proteger a vida em quaisquer das formas em que esta se apresente e para garantir um padrão de existência digno para os seres humanos desta e das futuras gerações.

Em nossa Carta Constitucional, conforme ensina Campos (2018), podem ser verificados princípios ambientais fundamentais para a instrução do Direito Ambiental, sem prejuízo de alcançá-los nas normas infraconstitucionais e nos fundamentos éticos e valorativos que, antes de tudo, devem nortear as relações entre o homem e as demais formas de vida ou de manifestação da natureza.

Com as referidas bases, o Direito Ambiental é ciência dotada de autonomia científica e, segundo Garcia e Thomé (2015), apesar de apresentar caráter interdisciplinar, obedece a princípios específicos de proteção ambiental, pois, de outra forma, dificilmente se obteria a proteção eficaz pretendida sobre o meio ambiente. Neste sentido, os princípios caracterizadores do direito ambiental acima elencados, têm como escopo fundamental orientar o desenvolvimento e a aplicação de políticas ambientais que servem como instrumento fundamental de proteção ao meio ambiente e, consequentemente, à vida humana.

Ainda neste contexto, a doutrina jurídica (GARCIA; THOMÉ, 2015, p. 17) apresentou um consenso quanto aos princípios existentes e aplicados. No entanto, mesmo sem haver um rol taxativo, pode-se elencar como os principais princípios jurídicos adotados na legislação brasileira, em matéria ambiental o Princípio da Dignidade da Pessoa Humana; Princípio do Direito Humano Fundamental ao Meio Ambiente Sadio; Princípio do desenvolvimento sustentável; Princípio da Prevenção e princípio da Precaução; 
Princípio do poluidor pagador; Princípio da Função Social e Ambiental da Propriedade e Princípio da participação comunitária.

Outros autores elencam outros princípios, todavia, apesar de, por vezes, terem nomenclaturas diferentes, possuem o mesmo conteúdo programático. Na lição de Pantoja (2019), os princípios do direito ambiental são frutos de uma construção jurídica originada no direito internacional ambiental, a partir das conferências ambientais internacionais. Por exemplo, a Conferência de Estocolmo (1972), a Cúpula da Terra ou Conferência do Rio (1992) e a Convenção Quadro das Nações Unidas Sobre as Mudanças do Clima (1992).

A elaboração das normas ambientais ocorreu forma caótica e desordenada, muitas vezes numa tentativa de conter crises ambientais ou a fim de dar respostas rápidas às descobertas científicas. Por conta disso, o surgimento gradual de princípios fundamentais facilitou a coerência do direito ambiental. Afinal, eles propiciaram o fio condutor indispensável de se localizar numa vasta gama de textos normativos.

Os princípios do direito ambiental foram elaborados para dar legitimidade jurídica aos Estados a criarem políticas públicas voltadas à proteção ambiental. Por isso, os princípios do direito ambiental possuem a função de ordenar a construção normativa ambiental internacional, regional e nacional.

Norteados nestes princípios, editam-se leis, normas, regulamentos entre outras espécies normativas que implementam medidas a conferir proteção ambiental e ordenar o uso dos recursos naturais, seguindo a diretriz geral prevista na Constituição brasileira.

Reforçando este ponto destaca-se o fato de que a Carta Magna de 1988 consagrou em matéria ambiental, o Direito de todos ao meio ambiente equilibrado, conforme se vê do artigo 225, abaixo colacionado:

Art. 225. Todos têm direito ao meio ambiente ecologicamente equilibrado, bem de uso comum do povo e essencial à sadia qualidade de vida, impondose ao Poder Público e à coletividade o dever de defendê-lo e preservá-lo para as presentes e futuras gerações. BRASIL, 1988.
Notadamente o artigo supramencionado traz consigo o fato de que as pessoas, destinatárias da legislação, possuem o direito ao meio ambiente equilibrado. Aliado a isso tem-se a expressa menção de tratar-se de um direito às presentes e futuras gerações.

No entanto, para que os destinatários deste direito possam gozá-lo, mister que o seu instrumento, qual seja, o meio ambiente, seja guardado de intervenções abruptas que venham a comprometê-lo.

Para tanto, as normas infraconstitucionais vêm ao encontro da política de busca à preservação ambiental, dentre as quais podemos destacar a Lei 6.938/81 (BRASIL, 1981) (anterior à Constituição, mas por ela recepcionada), que dispões sobre a Politica Nacional do Meio Ambiente, a Lei 9.605/98 (BRASIL, 1998) que dispõem sobre os crimes ambientais, a Lei 9.985/00 (BRASIL, 2000) que dispõe sobre o Sistema Nacional das Unidades de conservação, a Lei 12.651/12 (BRASIL, 2012) que instituiu o Código Florestal e ainda a Lei 10.257/01 (BRASIL, 2001) que instituiu o conhecido estatuto das cidades que estabelece diretrizes gerais da política urbana.

Todas essas legislações relacionadas, impõem restrições à utilização indiscriminada dos recursos naturais e ocupação desordenada dos espaços naturais entorno de nascentes, entre outros. É possível, portanto, vislumbrar que todas elas buscam a consecução de medidas que conferem proteção aos direitos humanos garantindo o meio ambiente saudável para as presentes e futuras gerações em uma consequente proteção à natureza.

Nos dizeres de Souza (2014), para que a diferenciação seja ainda mais nítida, passou-se a falar que os direitos da natureza são considerados direitos ecológicos, enquanto que os direitos ambientais seriam oriundos dos direitos humanos. Ressalte-se que o reconhecimento da natureza como titular de direitos não permite a conclusão de que a mesma goza de qualquer prevalência ou superação em relação aos direitos humanos.

Ao se elevar a natureza a titular de direitos, a Constituição do Equador tornou desnecessária a demonstração da ofensa a interesses humanos para se lançar mão dos instrumentos jurídicos próprios à proteção do meio ambiente e dos seres que o formam. No entanto, ainda na lição de Souza (2014) em casos concretos, nos quais um direito da natureza e um 
interesse humano venham a colidir, é necessário que seja feita uma ponderação dos interesses conflitantes. Na situação atual brasileira, por exemplo, há simples prevalência dos interesses humanos, enquanto que no Equador tal embate poderá ser discutido até mesmo nas Cortes Judiciais.

Todavia, ao nosso sentir, a natureza e o meio ambiente se equivalem na condição de sujeitos de direito no ordenamento jurídico brasileiro, pois, mesmo que os destinatários dos direitos, inicialmente, sejam os seres humanos, estes estão inseridos na natureza e são parte dela.

Igualmente, a natureza e o meio ambiente possuem na legislação brasileira normativas que inibem sua dilapidação, sendo também sujeita de direitos na esfera constitucional e infraconstitucional. Nesse ponto destaca-se, em termos normativos, a já citada lei 6.938/81 conhecida como PNMA (Política Nacional do Meio Ambiente) que instituiu o SISNAMA (Sistema Nacional do Meio Ambiente) (BRASIL, 1981). A referida Lei é um exemplo de legislação que aplica diversos princípios do direito ambiental, como os da Precaução, Prevenção e Poluidor-pagador, a fim de evitar a utilização indiscriminada dos recursos naturais.

Desta maneira, a Filosofia do Buen Vivir, foi incorporada indiretamente em nossa Constituição e nas normas infraconstitucionais, razão pela qual, os direitos da natureza também estão consagrados no Brasil.

\section{Considerações finais}

A filosofia do Buen Vivir originada nos povos andinos consolidou-se como um movimento de culto e respeito à natureza com a sua inclusão como sujeita de Direitos na Constituição do Equador.

Ocorre, todavia que o Buen Vivir não pode ser um modo de vida excludente do progresso e das conquistas da sociedade pós-moderna, mas deve ser uma compatibilização da busca da modernidade e de conquistas sociais e tecnológicas à preservação da natureza e de seus valores inserindo uma relação simbiótica entre o homem e a natureza.

E neste ponto os progressos alcançados nas mais diversas áreas da humanidade não retrocederão e, compatibilizar este avanço com a preservação do meio ambiente é o melhor caminho.

Assim agiu o legislador brasileiro, o qual, mesmo que não expressamente, adotou a natureza como sujeita de direitos, com um vasto arcabouço jurídico de proteção ambiental sustentado pelo artigo 225 da Constituição de 1988. A referida Carta magna, portanto, consagrou o direito à vida, à propriedade e ainda os demais direitos e garantias fundamentais, todos em consonância com a preservação do meio ambiente.

\section{Referências}

ACOSTA, A. O Bem Viver: uma oportunidade para imaginar outros mundos. Editora Elefante. São Paulo. 2016

ALBANESI, F. C. O que se entende por efeito "cliquet" nos direitos humanos? 2008. LFG. Disponível em: <https://lfg.jusbrasil.com.br/ noticias/104698/o-que-se-entende-por-efeito-cliquetnos-direitos-humanos-fabricio-carregosa-albanesi>

ALEXY, R. Sistema jurídico, principio jurídicos y razón practica. Doxa: Cuadernos de Filosofia del Derecho. n. 5, 1988.

ALEXY, R. Teoria dos direitos fundamentais. São Paulo: Malheiros, 2008.

AMORIM, L. B. A distinção entre regras e princípios segundo Robert Alexy: Esboço e críticas. Revista de Informação Legislativa, Brasília, n.165, jan./mar. 2005. Disponível em http:/www.senado.gov.br/web/ cegraf/ril/Pdf/pdf_165/R165-11.pdf>

ATIENZA, M.; MANERO, J. R. Ilícitos atípicos: sobre el abuso del derecho, el fraude de ley y la desviación de poder. Madrid: Trotta, 2006.

ÁVILA, H. Teoria dos princípios: da definição à aplicação dos princípios jurídicos. 7. ed. São Paulo: Malheiros, 2007.

BECK, U. Sociedade de risco: Rumo a uma outra Modernidade. São Paulo: Ed. 34, 2001.

BOBBIO, N. Principi generali di diritto. Novissiomo Digesto Italiano. XIII, Turín, 1966.

BRASIL. Constituição da República Federativa do Brasil de 1988. Brasília. 1988. Disponível em: $<$ http://www.planalto.gov.br/ccivil 03/constituicao/ constituicao.htm>

BRASIL. Decreto no 2.652, de 01 de julho de 1998. Promulga a Convenção-Quadro das Nações Unidas sobre Mudança do Clima, assinada em Nova York, em 9 de maio de 1992. In: BRASIL. Senado Federal. Protocolo de Quioto e legislação correlata. Brasília: Secretaria Especial de Editoração e Publicações, 2004. 
BRASIL. Lei 6.938, de 31 de agosto de 1981 . Dispõe sobre a Política Nacional do Meio Ambiente, seus fins e mecanismos de formulação e aplicação, e dá outras providências. Disponível em: $<\mathrm{http}: / / \mathrm{www}$. planalto.gov.br/ccivil_03/leis/16938.htm>

BRASIL. Lei 9.605, de 12 de fevereiro de 1998. Dispõe sobre as sanções penais e administrativas derivadas de condutas e atividades lesivas ao meio ambiente, e dá outras providências. Disponível em: $<$ http://www.planalto.gov.br/ccivil_03/leis/19605. htm>

BRASIL. Lei 9.985, de 18 de julho de 2000 . Regulamenta o art. 225, § 1o, incisos I, II, III e VII da Constituição Federal, institui o Sistema Nacional de Unidades de Conservação da Natureza e dá outras providências. Disponível em: $<$ http://www.planalto. gov.br/ccivil 03/leis/19985.htm>

BRASIL. Lei 10.257 de 10 de 2001. Regulamenta os artigos 182 e 183 da Constituição Federal, estabelece diretrizes gerais da política urbana e dá outras providências. Disponível em: <http://www.planalto. gov.br/ccivil 03/leis/leis 2001/110257.htm>

BRASIL. Lei 12.651, de 25 de maio de 2012. Dispõe sobre a proteção da vegetação nativa. Disponível em: <http://www.planalto.gov.br/ccivil_03/_ato20112014/2012/lei/112651.htm>

CACHICHI, R. C. D. A distinção entre princípios e regras como espécies de normas na obra teoria dos direitos fundamentais de Robert Alexy. Revista de Direito Público, Londrina, v, 4, n. 2, p. 1-11, maio/ ago. 2009.

CAMPOS, G. Princípios do Direito Ambiental. 2018. Disponível em: $<$ https://www.verdeghaia.com. br/principios-do-direito-ambiental/>

CANOTILhO, J. J. G. Direito Constitucional e Teoria da Constituição. 5. ed. Coimbra: Almedina, 2002.

DEL VECCHIO, G. Sui principi generali del diritto. Studi sul diritto. v. I. Milão, 1958.

DERBLI, F. O Princípio da Proibição de Retrocesso Social na Constituição de 1988. Rio de Janeiro: Renovar, 2007.

DILGER, G. O Bem Viver: Uma Oportunidade Para Imaginar Outros Mundos. 2017. Disponível: <https:// rosalux.org.br/o-bem-viver-uma-oportunidade-paraimaginar-outros-mundos/>

DWORKIN, R. Taking Rights Seriously. Londres: Duckworth, 1978.
ESSER, J. Grundsatz und Norm in der richterlichen Forbildung des Privatrechts. Ubingen: J. C. B. Mohr, 1956.

FACHINI, T. Direitos e garantias fundamentais: conceito e características. (2019). Disponível em: $<$ https://www.projuris.com.br/o-que-sao-direitosfundamentais/>

GARCIA, L. M.; THOMÉ, R. Direito Ambiental - Coleção Leis Especiais para Concursos. 8. ed. Salvador: Editora Juspodivm, 2015.

HART, H. L. A. The Concept of Law. Oxford: Oxford University Press, 2002.

LASSALlE, F. O que é Uma Constituição? São Paulo: Edições e Publicações Brasil, 1933. Disponível em: <http://www.ebooksbrasil.org/ eLibris/constituicaol.html>

LENZA, P. Direito Constitucional Esquematizado. 10. ed. São Paulo: Editora Método, 2006.

MIRANDA, J. Estudos Sobre a Constituição. Lisboa: Petrony. 1977.

SHIRAISHI NETO, J.; ARAÚJO, M. A. T. "Buen vivir": notas de um conceito constitucional em disputa. Fortaleza. Ed. Pensar. 2015.

NOVELINO, M. Direito Constitucional. 3 ed. São Paulo: Editora Método, 2009.

NUNES JUNIOR, F.; ALVES, M. Curso de direito constitucional. São Paulo: Saraiva, 2019.

PANTOJA, O. História dos princípios do direito ambiental. 2019. Disponível em: <https:// www.aurum.com.br/blog/principios-do-direitoambiental/>

SOBREVILLA, D. El modelo jurídico de reglas, principios y procedimientos de Robert Alexy. Isonomía, n. 4, abril/1996. Disponível em: <http:// www.cervantesvirtual.com/servlet/SirveObras/ doxa/01474063322636384254480/isonomia04/iso09. pdf $>$

SOUZA, D. R. N. A natureza como titular de direitos segundo a Constituição do Equador. 2014. Disponível em: <https://jus.com.br/artigos/34752/ a-natureza-como-titular-de-direitos-segundo-aconstituicao-do-equador $>$

TURINO, C. Bem viver, una alternativa a la idea de desarrollo. Revista PH [en línea], n. 101, p. 160-179, 2020. 